\title{
Algunas consideraciones críticas en relación con las aproximaciones historiográficas referentes a la coyuntura política electoral de 1939 en el Perú
}

\section{RESUMEN}

Se establece una crítica, que pretende cognoscitivamente ser lo más precisa posible, a determinadas e importantes aproximaciones historiográficas referentes a la grave coyuntura política-electoral de 1939 en el Perú. Y esto dada las serias limitaciones documentales y/o deficiencias interpretativas que aquellas aproximaciones presentan y dada también las funestas consecuencias fraudulentas derivadas del, en extremo vertical, contexto dictatorial.

Palabras Clave: Crítica; coyuntura; política; elecciones; dictadura; fraude; documentación; interpretación.

\section{Some critical consideration in relations to the historiographical approximations reserring to the political-electoral situation of 1939 in Peru}

\begin{abstract}
A critique is hereby provided which attempts cognitively to be as precise as possible, to certain and important historiographic explanations referring to the serious political-electoral situation of 1939 in Peru given the series of documentary limitations and/ or interpretative deficiencies that those explanations pose, and also given the disastrous fraudulent consequences derived from the extreme dictatorial context.
\end{abstract}

KeYwords: Criticism; historiography; situation; politics; elections; dictatorship; fraud; documentation; interpretation. 
a coyuntura política electoral de 1939 en el Perú ha sido uno de los momentos históricos más importantes vivido en nuestro país, tal como intentamos demostrarlo pormenorizadamente en el libro Dictadura, cultura autoritaria y conflicto politico en el Perú,1936-1939 (Molinari 2017); sin embargo, dada su derivación dictatorial, las aproximaciones historiográficas al respecto, supuestamente rigurosas y que cuestiono, son bastante limitadas, incluso imprecisas o confusas y no pocas veces erróneas.

Esas deficiencias en el rigor historiográfico, específicamente en términos metodológicos, tanto explicativos como comprensivos, provienen desde mi perspectiva interpretativa y mis investigaciones sobre dicha coyuntura de una seria limitación, básicamente en el uso y/o conocimiento de las fuentes primarias e incluso de las versiones publicadas de carácter testimonial y/o partidarias-oficiales por parte de los autores considerados, todos ellos, con una vasta e importante trayectoria en la investigación histórica y sociológica, y gozan de un merecido prestigio; pero al tratar esa coyuntura política electoral, no obstante el valioso prestigio académico que poseen, sus deficiencias son clamorosas.

De esa manera se constatan, evidenciándose una desigual incursión heurística en tales autores, las deficiencias en las afirmaciones y/o conclusiones que establecieron Julio Cotler (1978 y ediciones posteriores), Peter Klarén (2004), Contreras y Cueto (1999 y ediciones posteriores), así como Sinesio López y Milagros Barrenechea (2005 y 2019).

Veamos, entonces, las severas limitaciones observadas y cuestionadas en aquellas aproximaciones historiográficas a la coyuntura política electoral de 1939.

Así, el tan recordado e imprescindible Julio Cotler, en su libro Clases, Estado y nación en el Perú, se equivoca rotundamente cuando dice:

[...] en la medida que Prado constituía el vocero de la burguesía nacional progresista, tanto el APRA como el Parido Comunista le otorgaron el apoyo tácito asegurándole el triunfo electoral (p. 237).

Esto constituye un grave error a la luz de la documentación aprista emitida en aquella coyuntura política electoral dado que el APRA, en este caso, no establece ninguna propuesta encaminada al apoyo de la candidatura de Prado.

Peor aún, ¿quién en la dirección aprista, en aquel contexto, emite algún documento dándole a Prado aquella tipificación de supuesto vocero de la «burguesía nacional progresista»?

En la versión aprista oficial, con la correspondiente documentación (Soto Rivera 2002), se puede apreciar claramente la posición de la dirección aprista frente a la candidatura de Prado y que no tiene nada que ver, como observaremos, con lo afirmado por Cotler.

Es decir, en aquellas elecciones carentes de las mínimas garantías dado el abierto apoyo del dictador Benavides a la candidatura de Prado (Molinari 2017), y efectuadas desde el contexto de la promoción de un grave intento divisionista perpetrado contra el APRA, encabezado por los exdirigentes apristas de mando intermedio, Vásquez Lapeyre y Nazario Chávez, donde incluso se llega a publicar, de agosto a diciembre de 1939, una "Tribuna» apócrifa en frontal oposición a la dirección aprista y, en especial, a su líder Haya de la Torre (Biblioteca Nacional-Hemeroteca).

De esa manera, no era posible ningún tipo de apoyo de la dirección del PAP a la candidatura de Prado, pues tal promoción divisionista, a su vez, fue parte de la sinuosa instrumentalización política dictatorial de Benavides y Prado impuesta en aquella coyuntura; donde además de la agudización de la despiadada persecución contra la militancia aprista y su líder, promueven y sostienen, en lo fundamental, aquel grave intento divisionista. Persecución que se hace mayúscula cuando la dirección del PAP rechaza ceder y caer, como se verá, en esa ruta política instrumental de la dictadura (Molinari 2017).

En ese contexto, Roy Soto dice lo siguiente:

[...] en un primer momento Prado buscó el apoyo del Apra y se efectuaron las entrevistas clandestinas entre emisarios designados por el candidato y el Jefe aprista.

[...] Lo cierto es que no se llegó a concretar el acuerdo por cuanto en esos días Haya de la Torre estuvo a punto de perder la vida debido a los asaltos que se efectuaron en los refugios clandestinos que utilizaba en Chorrillos y Barranco. 
En la determinación aprista influyó, además, la clausura del diario La Prensa opuesto a la candidatura.

Con fecha 20 de octubre de 1939 se difundió un comunicado oficial del PAP, suscrito por Haya de la Torre, en el que daba a conocer a los apristas de toda la república que NO debían apoyar la candidatura de Prado por presentar la continuación del régimen de tiranía, estando también firmado por los miembros del CEN: Alfredo Saco Miró Quesada, Alcides Espelucín, Antenor Orrego, Juan de Dios Merel, Carlos García Ronceros y Luis Felipe de las Casas (pp. 361-365).

Así también, en una carta emitida por el propio Haya de la Torre y dirigida a Luis Alberto Sánchez pocos días después del «acto electoral», que se concreta ese 22 de octubre de 1939, Haya condena rotundamente lo que abiertamente consideraba un gravísimo fraude y le comunica, entonces, los preparativos insurgentes que la dirección del PAP proponía y, a su vez, con la búsqueda de la más amplia unificación de las distintas fuerzas políticas de oposición a la dictadura de Benavides.

Es decir, para Haya de la Torre lo que consideraba explícitamente como la tiranía de Benavides había preparado todo un contundente fraude y con lo cual, se entiende, que en tal contexto era imposible cualquier apoyo a la candidatura de Prado (V. R. Haya de la Torre-L. A. Sánchez. Correspondencia, 19241976, tomo I; 1982).

De esa manera, vemos que la dirección del PAP no propuso votar por Prado, ni por nadie, pues encontraron cerradas todas las salidas políticas dado el férreo contexto dictatorial encaminado al fraude y sólo así al «triunfo electoral» de Prado. De ahí que la dirección del PAP, y como precisa documentalmente Roy Soto, rechaza tajantemente cualquier apoyo a la candidatura oficialista de Prado.

Y en relación a esa supuesta condición de vocero de la «burguesía nacional progresista» que, según Cotler, viabilizaba el apoyo aprista a Prado, por el contrario Percy Murrillo Garaycochea, otro de los autores oficiales del Apra, premunido de los documentos del partido aprista y citando a Luis Alberto Sánchez, enfatiza que para el APRA Manuel Prado representaba a «el internacionalismo financiero-industrial» (Murillo 1976).
Entonces, se equivoca Julio Cotler con lo del "apoyo tácito» del APRA a la candidatura de Prado no solo por lo que se evidencia en ese tan elocuente documento emitido por el CEN del PAP aquel 20 de octubre de 1939, en el cual, como observamos citando a Roy Soto, se llamaba a la militancia aprista explícitamente a no votar por Prado sino porque, en ese contexto dictatorial, el PAP y su líder, tal como se dijo, eran víctimas de aquella grave persecución y porque, además, contando con el apoyo decisivo del dictador Benavides y de Manuel Prado se pretendió dividir orgánica y políticamente al Partido Aprista Peruano (Molinari 2017).

Asimismo, aquel proceso divisionista, en lo fundamental manipulado por la dictadura, y aquella grave arremetida represiva contra el aprismo y su líder se agudizó al fracasar aquel temprano intento de negociación política convocado por Prado y que como no llegaron a satisfacer las expectativas de subordinación dictatorial-instrumental los emisarios apristas incluso fueron detenidos y luego deportados. De allí, entonces, aquella precipitada disposición insurgente de la dirección del PAP como respuesta a todo ese sinuoso camino de recambio oficialistadictatorial (Molinari 2017).

Pero también se equivoca Julio Cotler cuando dice que el Partido Comunista Peruano brindó «un apoyo tácito" a la candidatura de Manuel Prado. No, tal apoyo, como se observa en el prolijamente documentado libro de A. Anderle, Los movimientos políticos en el Perú (1985), y en las fuentes primarias del propio PCP (Flores Galindo, comp. 1982), referentes a esa coyuntura, no tuvo nada de "tácito" sino fue explícito y entusiasta, incluyendo dos candidatos al Parlamento (donde estuvo el sindicalista Juan P. Luna) y la oficiosa asesoría de Martínez de la Torre.

Apoyo explícito y entusiasta del PCP dada la vertical y sinuosa línea estalinista, expresada, a su vez y en ese contexto, en la versión browderista y por ello asumida bajo tales patrones tanto en el ámbito interno como en el internacional (Molinari 2017).

Y continuando con esta incursión historiográfico-crítica sobre aquellas tan instrumentalizadas «elecciones» de 1939, accedamos ahora a los argumentos de Peter Klarén (2004). 
Aquí, y no obstante su trayectoria de riguroso historiador, Klarén también se equivoca gravemente al afirmar lo siguiente:

por su parte el APRA [...] se inclinaba hacia Prado considerando que su moderación y decidido antifascismo era más ventajoso para su Partido que su rival de línea dura.

Favorecidos por el conteo gubernamental de los votos y por la preferencia aprista que lo consideraba el «mal menor», Prado ganó fácilmente las elecciones. [...] Prado era un "conservador modernizante» que puso al Perú en un camino democrático después de una década de dictadura, al establecer un clima de mayor tolerancia hacia el Apra y la izquierda.

El nuevo Presidente reconocía que su elección se debía a los votos apristas.

[...] En consecuencia estableció una alianza tácita con el APRA.....» (p. 345).

Es decir, observamos aquí conclusiones estrepitosamente erróneas. ¿Y por qué llega Klarén a estas tan erróneas conclusiones? Pues desde las versiones bibliográficas-oficiales del PAP, testimonios y fuentes primarias apristas no fue así. Y, metodológicamente, todo esto lo verificamos desde nuestras propias indagaciones, compulsa y contraste de fuentes (Molinari, 2017).

Entonces, es pertinente la pregunta: ¿estamos frente a un nuevo tipo de historia políticamente correcta?

Pregunta pertinente ya que con ese tipo de relato «histórico» tan arbitrario las interpretaciones que se pueden establecer sobre aquella dramática coyuntura política de 1939 sólo pueden producir nuevas y fantasiosas "conclusiones» prejuiciosamente ideologizadas.

Y enfatizamos en eso, pues en la dramática coyuntura enfocada lo que muestran documentalmente Luis Alberto Sánchez, Percy Murillo, Roy Soto y el propio Haya de la Torre, además de aquel rotundo rechazo de la dirección aprista a la candidatura de Prado y a la que explícitamente denominan «tiranía» de Benavides, esas «elecciones» de 1939 las "ganó» Prado desde el más escandaloso fraude y no por ser simplemente favorecido por el "conteo gubernamental» y mucho menos por la preferencia aprista.

Al respecto, Roy Soto cita a Rafael Belaunde dado que ante tal descarada manipulación fraudulen- ta muy dignamente renunció a su cargo de embajador del gobierno de Benavides en Chile en calidad de protesta y frente a lo que Belaunde calificó abiertamente como «fraude electoral» (Soto, R. 2002).

Además, sobre aquel escandaloso fraude está lo aseverado en sus Memorias por Carlos Moreyra y Paz Soldán, citado por E. Chirinos Soto (1986) y, sobre todo, aquella información hecha pública 31 años después y enfatizada por Luis Alberto Sánchez (1981) referente a las ánforas y documentación del sufragio electoral de 1939, correspondientes a la provincia de Lima, halladas escondidas en 1970 y luego de una demolición urbana.

Asimismo, es totalmente erróneo lo que dice Peter Klarén sobre la supuesta actitud «tolerante» de Prado frente al PAP durante su gobierno, pues como afirma Roy Soto (op. cit.), la dureza represiva impuesta contra el Apra por la dictadura de Benavides continuó plenamente bajo el gobierno pseudodemocrático del magnate Manuel Prado, es decir hasta iniciado 1945, dado que se siguió con aquella persecución policial contra la militancia aprista y, en especial, contra su líder Haya de la Torre.

Así pues, se mantuvo en la más estricta ilegalidad al Apra, se mantuvo también en el destierro a sus principales dirigentes y, de esa manera, tanto la persecución como la cárcel era la contundente respuesta gubernamental de Prado frente al activismo de la militancia aprista leal a Víctor Raúl Haya de la Torre así como al CEN del PAP.

Ante todo aquello resulta desproporcionado, pero también elocuente, en términos historiográficos, que Peter Klarén, como se aprecia en la página 527 de su controversial libro, haga un exagerado elogio al libro de Historia del Perú contemporáneo de Contreras y Cuento (1999 y ediciones posteriores) del cual dice: «es el mejor examen, más amplio y actualizado sobre la historia del Perú contemporáneo».

$\mathrm{Y}$ esto es, entonces, historiográficamente muy cuestionable, pues el libro de Contreras y Cueto presenta graves errores y omisiones referentes a la década de 1930. Así, llegan a afirmar, incluso, que Manuel Prado en 1939 «lideró al Frente Patriótico» (p. 218).

Es decir, Manuel Prado que encabezó políticamente a la Concentración Nacional habría liderado, desde la imaginación de Contreras y Cueto, a su archirrival en aquella coyuntura política-electoral de 1939, el Frente Patriótico. 
Asimismo, es también muy precipitada la afirmación de Klarén sobre aquel supuesto «decidido antifascismo» de Manuel Prado en 1939, pues en 1938 el entonces poderoso Banco Popular de la familia Prado fue uno de los principales patrocinadores del periódico falangista Unidad, órgano de la delegación espańola de la FET-JONS, y publicado en Lima durante aquellos años. Periódico abiertamente fascista y activo promotor en el Perú del franquismo bajo la entusiasta acogida de la dictadura de Benavides y cuando Manuel Prado, amigo íntimo del dictador, era el presidente del BCR (Molinari, 2017).

Veamos, por último, lo que Sinesio López y Milagros Barrenechea presentan en su aproximación a dicha coyuntura (2005 y 2019).

Así, en aquel texto y cuando focaliza la coyuntura político-electoral de 1939, nos encontramos con una entrada consistente pero que deviene en imprecisa, con errores y, a su vez, limitada en el uso de fuentes. De ahí que, por ejemplo, no se explayan sobre aquel escandaloso fraude organizado por el dictador Benavides a favor del candidato Manuel Prado y ante esa carencia sólo consideran, ambiguamente, que hubo un "valiosísimo» apoyo de Benavides (p. 127).

Asimismo, sobre la participación del supuesto «sector» del Partido Unión Revolucionaria que apoyó la candidatura de Prado, se habla de un «sector no fascista» dirigido por Cirilo Ortega ignorando que no se trataba simplemente de "un sector» sino de una corriente escindida varios meses atrás del urrismo orgánico y leal, desde la clandestinidad dada su ilegalización, al líder Luis A. Flores.

Esa corriente escindida, a su vez, al asumir sumisamente el apoyo al candidato oficialista usurpó el nombre del Partido Unión Revolucionaria para, de esa manera, lograr el reconocimiento legal del JNE lo cual contribuyó formalmente, desde toda una maniobra urdida por la dictadura, al mantenimiento en la ilegalidad del Partido Unión Revolucionaria, orgánico y liderado por Luis A. Flores, dada la condición de promotor, desde la clandestinidad, del denominado Frente Patriótico con la candidatura de José Quesada, a su vez, único opositor electoral del candidato oficialista. Esto denota, entonces, las contradicciones «intraoligárquicas» dada pues la complejidad del devenir de los poderes fácticos en el Perú bajo las densas particularidades de aquella coyuntura política y desde aquel contexto dictatorial (Molinari, 2017).
Cabe agregar que aquella escisión del pseudo PUR, como se dijo, se fue forjando bastante antes y se concreta en un "congreso" realizado en diciembre de1938. Asimismo, la sumisión de Ortega, el líder escisionista, al dictador Benavides se produce poco tiempo después de la frustrada rebelión de febrero de 1939 y encabezada por el General Rodríguez. Allí, en dicha rebelión, participó Ortega y su corriente ya escindida por lo que fue encarcelado luego de derrotado el intento insurreccional. Así, y para lograr su libertad, Ortega decide someterse políticamente a la dictadura de Benavides y con ello su posterior apoyo a la candidatura oficialista de Prado (Molinari, 2017.)

Sobre el PAP, la impresición es acompańada, también, por la ambigüedad. Es así que los autores, erróneamente, parten de un supuesto apoyo electoral del Apra a Prado (p. 110).

Luego, matizan tan contundente como errónea aseveración, haciendo referencias (esta vez adecuadamente) a aquellas "negociaciones estériles» así como incursionando, pero desde un breve y limitado enfoque, al intento divisionista encabezado por Vásquez Lapeyre que padeció el PAP. Al respecto, se dice muy poco de tal intento divisionista y que supuso, como indicamos, todo un intento de ruptura contra el PAP y el liderazgo de Haya de la Torre.

Sin embargo, también mencionan al periódico apócrifo, es decir la pseudo "Tribuna»(vocero de aquel grave intento divisionista) sobre lo cual, acertadamente, sí señalan que fue apoyado por Manuel Prado. Pero, extrańamente, los autores dicen muy poco sobre la labor divisionista, rupturista y de paralelismo orgánico que sistemática y detalladamente se puede apreciar en aquella "Tribuna» apócrifa (Molinari, 2017).

No obstante, sí señalan que Vásquez Lapeyre convocó a una "Asamblea nacional del Partido» y a unos "comités» que acordaron abolir «la organización vertical». Pero, no ubican aquello en el devenir instrumental que tanto el dictador Benavides (no sólo el candidato oficialista) y Manuel Prado habían trazado para viabilizar la concreción del fraude electoral.

Es decir, a su vez, los autores omiten, en lo fundamental, una imprescindible indagación sobre el contexto orgánico del Apra bajo la dictadura de Benavides (como se dijo, bajo la más despiadada persecución, la ilegalidad y de toda una complejamente soterrada clandestinidad pero, sin embargo, política- 
mente muy activo, emitiéndose incluso La Tribuna clandestina, etc.) con relación a ese gravísimo intento , aunque frustrado, de ruptura orgánica, paralelismo y desconocimiento frontal del liderazgo de Haya de la Torre (cargado siempre de un intenso mesianismo carismático para sus adeptos) así como de la estructura directriz del Partido Aprista, con lo cual ese relato deviene en limitado y confuso.

Así, al no considerar las especificidades orgánicas del PAP en ese contexto dictatorial de dura persecución y de la más estricta clandestinidad (Molinari, 2017), para los autores las acciones paralelas, divisionistas y propradistas del grupo escindido, y entonces ya pseudoaprista encabezado por Vásquez Lapeyre y también por Nazario Chávez, en ese contexto enemigos declarados y frontales de Haya de la Torre, de la dirección y de la línea política del PAP (Molinari, 2017) habrían correspondido, curiosamente, al apoyo otorgado a Prado de «un sector aprista ... aunque parcial y minoritario» (p. 126).

Es decir, esta aproximación de Sinesio López y Milagros Barrenechea si bien es valiosa en sus búsquedas, sin embargo y no obstante las diversas pistas útiles que presentan, en lo sustancial aporta poco al conocimiento de la coyuntura político-electoral de 1939, pues, como observamos, constituye un enfoque limitado, por momentos impreciso y, sobre todo, sus omisiones son elocuentes.

\section{Bibliografía}

Anderle, Adam (1985). Los movimientos politicos en el Perú. La Habana: Ed. Casa de las Américas.

Cotler, Julio (1978 y ediciones posteriores). Clases, Estado y nación en el Perú. Lima: Ed. IEP.
Chirinos Soto, Enrique (1986). Historia de la República. 1821-1985. Lima: Ed. Científica.

Contreras, Carlos y Cueto, Marcos (1999 y ediciones posteriores). Historia del Perú contemporáneo. Lima: Ed. IEP-PUCP-UP.

KLARÉN, Peter (2004). Nación y sociedad en la historia del Perú. Lima: Ed. IEP.

López, Sinesio y Barrenechea, Milagros (2005 y 2019). Perú, 1930-1968: competencia y participación en el Estado oligárquico. En: Cristóbal Aljovín y Sinesio López (Eds.) Historia de las elecciones en el Perú. Lima: Ed. IEP.

Molinari Morales, Tirso Aníbal (2017). Dictadura, cultura autoritaria y conflicto político en el Perú. 19361939. Lima: UNMSM.

Murillo Garaycochea, Percy (1976). Historia del APRA 1919-1945. Lima: Ed. Atlántida.

Soto Rivera, Roy (2002). Victor Raúl, el hombre del siglo XX. Lima: Ed. Instituto Víctor Raúl Haya de la Torre.

\section{Documentos publicados citados}

V. R. Haya de la Torre-L.A. Sánchez, Correspondencia 19241976. Tomo I (Mosca Azul Editores. Lima, 1982).

Documentos comunistas y procomunistas, Perú 19171945. En: Alberto Flores Galindo. El pensamiento comunista 1917-1945. Selección, prólogo y bibliografía. (Mosca Azul Editores. Lima, 1982).

\section{Fuentes primarias citadas}

Periódico La Tribuna (apócrifa) Serie 1939. Lima. (Biblioteca Nacional- Hemeroteca).

Periódico La Tribuna - Clandestina -. Lima, 20 de mayo y 16 de Junio de 1937. (Archivo General de la Nación. Documento Prefecturales).

Periódico Unidad. FET-JONS. Lima, 1938 a 1941.

(Hemeroteca Municipal de Madrid-España). 